University of Nebraska - Lincoln

DigitalCommons@University of Nebraska - Lincoln

H. W. Manter Laboratory Library Materials

9-1917

\title{
On the Structure and Classification of North American Parasitic Worms
}

Henry Baldwin Ward

University of Illinois

Follow this and additional works at: https://digitalcommons.unl.edu/manterlibrary

Part of the Parasitology Commons

Ward, Henry Baldwin, "On the Structure and Classification of North American Parasitic Worms" (1917). H. W. Manter Laboratory Library Materials. 15.

https://digitalcommons.unl.edu/manterlibrary/15

This Article is brought to you for free and open access by DigitalCommons@University of Nebraska - Lincoln. It has been accepted for inclusion in H. W. Manter Laboratory Library Materials by an authorized administrator of DigitalCommons@University of Nebraska - Lincoln. 


\section{The Journal of Parasitology}

\begin{tabular}{llr}
\hline Volume 4 & SEPTEMBER, 1917 & Number 1 \\
\hline \hline
\end{tabular}

\section{ON THE STRUCTURE AND CLASSIFICATION OF NORTH AMERICAN PARASITIC WORMS *}

\section{Henry B. WARD}

For many years I have been engaged in the study of parasitic worms from North American freshwater hosts, mostly fish; during this time I have had opportunity to examine and compare material from a large number of localities embracing many widely separated points. In this work I have been aided very greatly by studies on individual groups undertaken and published under my direction by various graduate students to whom my obligation is freely expressed here. In connection with this work it has been necessary to examine critically all original records of parasites from similar hosts and to endeavor to reach a positive determination of the parasite under discussion in each case. This is not a simple matter, as the records were often made on the basis of a rapid preliminary examination; furthermore, the total lack of special reference works on these groups led to the recording of parasitic species under general names taken from the older European writers, and these names are often wanting in definite significance.

My work has naturally led to the discovery of new facts regarding the structure of the forms studied and has compelled me to introduce new names and to rearrange forms so as to express better their correct relationships in the light of more perfect knowledge of their structure. Such changes are of course unfortunate in that they make it difficult to trace the continuity between the new and the old in zoological literature; they are nonetheless essential if the student is to apprehend the true character and affiliations of the forms with which he comes in contact. It has been my fixed principle never to make any changes until I was personally familiar with the form discussed or had acquired such acquaintance with its structure as to know that some change was inevitable and that the proposed modification was defensible on morphological grounds. Most of the questions involved in the changes listed later in this paper have been submitted to the criticism of advanced workers in the field, or discussed before graduate classes for some years so that they may be regarded as seasoned changes.

* Contributions from the Zoological Laboratory of the University of Illinois, No. 94. 
Some of the more general results of my work have been included in brief form in synopses of the Parasitic Flatworms and Parasitic Roundworms which constitute two chapters in Freshwater Biology by Ward and Whipple just being published by John Wiley and Sons, New York. It seems to me wise to print here in outline the most important new material regarding the structure and classification of the parasitic forms discussed in these chapters as there are items which might easily escape notice and thus lead to confusion if published only in a textbook. The work just cited gives complete summaries of the North American forms in the groups mentioned and the place of the items discussed later in this paper may be precisely determined by reference to it. These items are arranged here in the order in which they are taken up in the book, and this is the systematic arrangement. The student will also find there an abundance of illustrations to demonstrate the points discussed here.

\section{TAXONOMIC CHANGES AMONG TREMATODA}

The genus Polystoma established by Zeder in 1800 is well known thru the common European type, $P$. integerrimum, generally employed in text books to illustrate the group of monogenetic termatodes. Several species from North America have been carefully described by Stunkard (1917). These forms stand out distinctly when compared with the European type and clearly constitute a separate section of the genus to which I have given the name Polystomoides. This subgenus which further study may show to be of generic rank is characterized by the presence of a short uterus containing only a single egg whereas the European type possessed a uterus of several coils with numerous eggs. Stunkard has also pointed out considerable differences in the structure of the suckers on the caudai disc. As type may be designated P. (Polystomoides) coronatum (Leidy 1888) from the common food terrapin.

As the cause of an epidemic among sparrows at Madison, Wisconsin, Cole (1911) reported under the name of Monostoma faba a trematode that in reality differs distinctly from the European species. The form of the ovary, the extent of the vitellaria, the dermal spines, and other details of structure disagree with the recent description of Kossack who moreover assigned Rudolphi's species to his new genus Collyriclum. The American form constitutes a new species in this genus and to it the name Collyriclum colei may be given. The position of this genus is so isolated among the monostomes that a new family must be created for it. This may be characterized as follows: 
CollYRICLIDAE Ward. Small to moderate sized monostomes with discoidal, compressed, not muscular body, broader than long. Oral sucker weak; pharynx present; ceca simple, long, capacious, not united. Genital pore ventral, near center of body. Vitellaria follicular, scanty, antero-lateral; ovary much lobed, asymmetrical. Uterus posterior, in irregular coils which show an anteroposterior tendency, terminal region enlarged. Testes oval, symmetrical, behind ovary. Eggs very small. Adults parasitic in dermal cysts on abdominal surface of skin in birds.

What is probably the same species has also been found parasitic on sparrows at Boston, Mass. Its appearance is concurrent with periods of wet weather.

In 1902 MacCallum described an interesting parasite from the lungs and air passages of the river snapping turtle (Chelydra serpentina) found in Ontario, Canada. To this he gave the name of Heronimus chelydrae. In 1914 Barker and Parsons described a very similar form from the lungs of Chrysemys marginata taken in Minnesota, and also of various other turtles from Nebraska. This parasite they named Aorchis extensus. I have collected specimens from Illinois, Indiana, and Michigan of what is probably the same species. These two forms are so much alike that they may prove to be identical or at least to belong to the same genus, but they are in some respects very different from any other monostomes known, and I have established for them a new family with the following characters:

Heronimidae Ward. Moderate sized monostomes with thick, elongate, soft body, slightly flattened, tapering toward both ends. Oral sucker weak, pharynx large, esophagus short or absent; ceca simple, narrow, extending to posterior tip but not united. Vitellaria compact tubular; uterus with four longitudinal regions; genital pore ventral to oral sucker, near anterior tip. Testis tubular, small, copulatory apparatus poorly developed. In lungs of turtles, northern North America.

Among the amphistomes Stunkard (1917) described a very peculiar form in which the oral sucker is subterminal and the acetabulum is divided by a transverse ridge into two pockets; this form which he named Zygocotyle ceratosa will not fit into any existing subfamily in the amphistome group, and for it must be made a new subfamily, the Zygocotylinae, which is characterized prominently by features just mentioned, and also by the lobed testis and the absence of a cirrus;

Among the distomes a number of changes seem necessary. The well-known parasite of native American herbivors, which was first named Distoma magnum by Bassi in 1875, has been included heretofore in the genus Fasciola, altho it has no distinct anterior cone, set off from the main part of the body, and the vitellaria are confined to the region ventral to the intestinal branches. The suggestion of Odhner that this form should be made a new genus seems thoroly justified by renewed study, and for it I propose the name Fascioloides with the type Fascioloides magna (Bassi 1875). 
Among the Echinostomes a species from the loon (Gavia imber) and from Bonaparte's gull (Larus philadelphia) was described by Gilbert (1905) as Echinostoma spinulosum Rudolphi; it can not be that species. From Gilbert's description which is good tho not complete I regard it as a member of the genus Stephanoprora Odhner 1902 to which the name Stephanoprora gilberti is now given.

Much confusion has been introduced into the family of the Azygiidae by the formation of new genera for forms which are merely extreme types of the genus Azygia. This is a powerfully muscular distome and may be greatly distorted in the process of preservation. Specimens taken from a single host at the same time and preserved in the same way often present marked external differences in size and form. The genera Megadistomum of Leidy and Stafford, Mimodistomum of Leidy, and Hassalius of Goldberger are instances of such extreme specimens that really belong to the single genus Azygia. These genera must accordingly be suppressed. Altho many records were found of the occurrence in North America of the common European species Azygia lucii Müller (often wrongly called $A$. tereticolle), the study of a great number of supposed specimens from different localities and hosts has furnished no evidence of its presence here, and I regard the earlier records as erroneous and due to confusion with other native species.

Among those distomes of the Allocreadiidae which have a group of muscular papillae around the oral sucker, Stafford (1904) separated Lander's Distoma petalosum as a new genus Acrodactyla from Crepidostomum and Bunodera. The separation is justified, but the name proposed is preoccupied, and I have substituted Acrolichanus with the type species $A$. petalosa (Lander). Stafford states that this form which is common in the intestine of the Lake sturgeon (Acipenser rubicundus) in the Great Lakes and St. Lawrence river, is "on the authority of Looss the D. auriculatum Wedl of Linton." I am unable to accept this conclusion or the comment of Odhner that $A$. petalosa Lander is a synonym of $A$. lintoni Pratt. By the courtesy of C. $\mathrm{H}$. Lander I have the original drawings of his form, as yet unpublished. A careful comparison of the details in the drawing with the evidence at hand on the other species noted is adequate to establish the distinctness of Lander's type. More data on this group will be published soon.

In 1910 H. L. Osborn established the genus Cryptogonimus to contain a species, $C$. chyli, he had found in the black bass and rock bass from Lake Chatauqua. The attempt to include this form in a systematic treatment of the distomes has necessitated forming a new subfamily for it, characterized as follows: 
Cryptogoniminae Ward. Very small, spinous distomes, of uniform width, with bluntly rounded ends. Oral sucker relatively large and prominent. Ventral sucker double, minute, enclosed in pocket with genital pore between the two parts. Prepharynx, pharynx, and short esophagus present; crura extend to anterior margin of testes. Excretory vesicle Y-shaped, forking at oviduct, anterior branches reach to pharynx. Testes elongate, parallel, dorsal, in posterior third of body; seminal vesicle convoluted, prominent; no cirrus or sac. Ovary ventral, proximate to testes, slightly lobed. Vitellaria scanty, lateral, in central region of body. Uterus with descending ramus on right, slightly coiled, extending to posterior end, ascending ramus returning on left, crossing in front of ovary and passing on right to genital atrium. Eggs small, dark. In alimentary canal of fresh-water fish.

The location of this subfamily is uncertain, but wherever placed it is somewhat isolated. Odhner would include its type genus Cryptogonimus and also Caecincola in the Acanthochasmidae; in that event they both must be regarded as having lost the crown of spines characteristic of the family and are sufficiently distinct to justify the formation of separate subfamilies, at least for the genus Cryptogomimus.

Odhner (1910) has given a very careful analysis of a complex group of distomes which he names the Lepodermatidae. The family is, however, substantially equivalent to Lühe's Plagiorchiidae, and while Odhner's emendations in the description should be accepted it seems wise to retain the earlier name. This very complex group is richly represented in the North American fauna and it is not unlikely that further study will show the need of splitting it up into two or more families. The precise structure of most North American representatives in the group is too poorly known to justify such a step at present. Among the genera included here are the frog lung flukes belonging to Pneumonoeces, recently worked over by Cort (1915). Looss has given such a thoro analysis of generic characters for these forms that one North American group must be separated as a new genus to which the name Pneumobites may be given; Pn. longiplexus (Stafford 1902) is the type of the genus. It is characterized by elongate lateral and nearly symmetrical testes, and lobed ovary in contrast with the round, median testes and entire ovary of Pneumonoeces. The forms are larger and thicker bodied than Pneumonoeces and the extra caecal longitudinal folds of the uterus are more pronounced, reaching nearly the length of the body. Pneumobites breviplexus belongs also in this new genus.

\section{LARVAL STAGES OF TREMATODA}

Some confusion has crept into the literature by virtue of inexact use of the terms employed to designate larval stages of trematodes. The cercaria is the youngest stage in the sexual generation and is produced in a redia or sporocyst; it has ordinarily a period of free existence and a caudal appendage used in locomotion. In exceptional cases the free stage is suppressed and the transfer is passive. The tail may 
be lacking and to such forms the name cercariaeum has been given; this term is a convenient group designation to include all cercariae that are at birth tailless and does not properly embrace such as secondarily throw off the tail. The rejection of the tail regularly occurs when the larva encysts and at the same time there is discharged the secretion of the cystogenous glands which in many free cercariae are very conspicuous structures. These two changes mark the transition from the cercaria stage to the young or agamic distome, and after they have occurred the larva may no longer rightly be termed a cercaria. The use of the term encysted cercaria for this stage is confusing and should be discontinued; the collective name Agamodistomum was introduced by Stossich in 1892 for this condition. From this point the change into the adult distome is merely a process of growth in size and differentiation of the sex organs. The agamodistomum stage is often only transitory as when the cercaria introduced into the alimentary canal of a final host rejects the tail and enters at once on the growth period that yields the adult fluke; it may, however be encysted in the flesh of some secondary host in which relatively unchanged it awaits the transfer to a final host before the growth period sets in. There is, however, no morphological distinction between the larvae in these two instances and no call for separate designations. A review of the literature on North American trematodes shows many cases in which agamic distomes have been described as cercariae. The rectification of these errors will aid in the elucidation of the various life histories involved.

\section{MORPHOLOGY OF NEMATODA}

Among the Nematoda s. str. it has been the custom to recognize a number of groups of family rank, and no attempt has been made to ascertain the relations of these families to each other or to form of them higher groups. To be sure, some recent workers have exalted the families of earlier workers to superfamilies, and this change seems both advisable and calculated to aid in their more adequate interpretation, but they remain none the less isolated and unrelated subdivisions. I am of the opinion that more precise study of the morphology of these groups will furnish the basis for interpreting their relation to each other. In line with this I wish to call attention briefly to some results of morphological studies which I think serve to clear up the situation in part at least.

In describing nematodes, terms have been used loosely which should have a definite morphological significance, and the confused usage has served to conceal distinctions that exist clearly. One such case concerns the designation of the specialized region surrounding the mouth. All sorts of structures developed at this point are called lips, and various sorts of projections surrounding the buccal orifice are designated 
a capsule. If one examines with care the oral armature one finds a number of distinct types of structure, each of which shows various modifications, but in most cases the fundamental type comes out clearly after study if not at first inspection. Three types which are easily distinguished I propose to call lips, jaws, and capsule, giving to each term a definiteness which accords with the condition in the old and well known examples of each and restricting each term to conditions which agree morphologically with the typical case.

True lips are best illustrated by Ascaris (Fig. 1). The anterior end of the body viewed en face shows three lobed projections which are varied in form and detail of structure in a manner characteristic of individual species, but which always hold the same relations to the planes of symmetry. One, the large lip, is dorsal, whereas two others, smaller, are ventral. That the large lip is to be interpreted as the fusion of two separate parts may be seen in the size, the two papillae it bears, and in other details of structure. This lip occupies the entire upper (dorsal) semicircle of the oral circumference and the line which separates it from the lower lips conforms to the lateral plane of symmetry. On the other hand the two inferior lips are clearly dextral and sinistral, being divided by a narrow slit that lies in the ventral half of the sagittal plane. These lips work as a three-parted organ, gripping rather weakly small objects that are drawn up between them. The orifice in this case is tripartite with the main axis lateral and the secondary axis extending ventral at right angles from the former.

True jaws are best illustrated by Camallanus (Fig. 3). The oral armature has only two distinct parts, and these are divided along the median line, the slit separating them being dorso-ventral and the parts symmetrical on the right and left. As seen in use this type of structure is distinctly a grasping organ; the parts move against each other with a powerful action and hold with vise-like grip. In the typical case, each part resembles in general appearance the shell of a Pecten and at the outer margin the two fit closely on each other. As the body of the nematode ordinarily lies on its side, such a structure may appear like a capsule, because the dorso-ventral slit is not apparent, but if the head is rotated carefully true jaws are easily distinguished from the true capsule - the type to be described next.

The oral capsule (Fig. 2) is spherical or cup-shaped, as seen best in the strongyles in which it presents great variety in individual details but a clear agreement thruout the group in fundamental features. At the anterior pole the sphere is cut off by a plane at right angles to the long axis of the worm so as to leave a circular orifice which is less frequently oval when the capsule is compressed laterally, but which is not a narrow dorso-ventral slit. The capsule is furthermore possessed of a considerable cavity which may be itself nearly spherical and which 
in the higher or modified types carries on its inner wall cutting and piercing organs such as teeth, lancets, etc., as in the various hookworms. The oral margin of the capsule may be papillate, serrate, or ornamented by fine spines as in many sclerostomes.

Perhaps the most invariable and characteristic feature of the oral capsule proper is its rigidity; while the internal features impart to it a definite bilateral character, the external form is unspecialized or at most radial in type. Its function agrees fully with this. The capsule itself is immobile and works as a cupping or sucking organ; and the internal structures move and by piercing or tearing the tissue wall to which the cup is applied, release fluid materials or torn fragments of cellular character which are drawn down the esophagus to serve as nourishment.

Not all oral armatures described for nematodes can be reduced to these three types. In many cases the data are too general and inadequate to permit of any decision as to the fundamental plan of structure represented. More exact study of this region will result in demonstrating the morphological resemblance to the types described above of some mouth parts yet poorly known. Those forms in which the mouth parts are least differentiated are most difficult to interpret and classify. Perhaps it will be necessary to recognize an undifferentiated type with only a few papillae around the oral opening, and it may well be that further knowledge will justify the designation of still other types of oral armature. Meanwhile it is important in the interests of accuracy and clarity to keep at least these three or four types distinct and to examine as many nematodes as possible in order to determine how far they conform to the morphological plans described or depart from them. The exact application of this test in recent work (Ward and Magath, 1917) and in other cases yet unpublished has been of marked service in reaching conclusions as to the true relationships among the Nematoda.

Another morphological factor which deserves emphasis is the structure of the esophagus. The most common type is that seen in the ascarids. It is pronouncedly muscular in type, with the fibers transverse to the long axis of the organ and conspicuous on first examination as cross lines. This esophagus is tripartite in cross section and is a powerful pumping organ. (Fig. 11.)

A type of radically different character is the capillary esophagus long known and exploited as a diagnostic feature in the trichina and whipworm. It consists of a row of cells pierced thruout the entire length by a delicate tube of minute caliber. This tube has evidently no power of changing form or caliber in functioning and is a sucking organ fitted to the ingestion of fluid nourishment exclusively. The various nematodes which possess such a capillary esophagus I have 
grouped together in a suborder, the Trichosyringata in contrast with those having a muscular esophagus which form the suborder, Myosyringata.

Among the Myosyringata one may observe some conspicuous modifications of the simple muscular esophagus just described. Possibly the most marked of these is the development of two specialized regions in the canal. The first is purely muscular and conforms to the simple muscular type except that it has no specialized region at the posterior end and is separated by the second region from the chyle stomach or intestine in which the process of digestion actually occurs. There is at most a line, partition, or constriction between the first or muscular region of the esophagus and the second. The latter is not uniform in appearance and may even be muscular in character like the first region. Usually, however, it is granular in appearance rather than striated and has more opaque walls. It terminates posteriorly in the valve or other special apparatus which marks the entrance into the intestine. Its function has not been clearly demonstrated, but it seems not to be a pumping organ.

In forms having a double esophagus various degrees of specialization may be noted. In the simplest case, Haplonema (Ward and Magath, 1917) one can see only a transverse partition (Fig. 12) dividing the esophagus into two regions which are both apparently muscular, but which differ in precise optical appearance so as to indicate functional differences between them. In other cases the distinction in histological character is more marked, but the separation between the two parts is not much more distinct. Finally, in Camallanus a deep constriction divides the anterior region very clearly from the posterior. In such cases the second part is easily overlooked and the description of the first region gives the worm an apparent likeness to the Ascarid type with a simple muscular esophagus. (Figs. 13, 14.)

One finds considerable range in the length, both absolute and relative, of the two regions of the esophagus. In the simplest case yet recognized (Haplonema) the total of both regions is not more than the simple muscular esophagus, but in the forms like Camallanus each region is so long that together both constitute a conspicuous part of the total length of the worm.

The double esophagus is one of the most characteristic features in the structure of nematodes included in the Spiruroidea and its occurrence may be confined to that group exclusively.

Some confusion also exists in description of the structure of the specialized caudal end in the male because of indefiniteness in the use of terms. In many males one finds lateral cuticular expansions about the caudal end which are utilized as grasping organs in copulation. The term bursa has been often used for all these organs; one may, 
however, early recognize at least two types that are morphologically distinct, and that may well receive different names. In one type the organ consists of semicircular expansions that include the extreme posterior tip of the body, joining behind it and indicating the median line by a deep notch or furrow where the two folds come together. The organ shows a series of lines or bands that radiate like the sticks of a fan from a basal point on each side, diverging as they approach the periphery of the fold. This organ which I propose to call the bursa is shaped like a shallow cup or saucer and forms a conspicuous suckerlike termination for the caudal end of the male in the true Strongyloidea. (Figs. 8-10.)

The second type often resembles the first in a superficial way, but on more particular examination shows clear differences. The cuticular expansions are narrow linear folds; they extend along the sides of the body for some distance anterior to the caudal tip, but do not reach posteriad beyond the tip. The outer margin of the fold is nearly parallel to the body, but approaches it slowly, since the fold is broadest near its anterior end and tapers to zero between the anus and the posterior tip of the body. These folds possess bands that are generally speaking perpendicular to the long axis of the body, being parallel to each other and not radiating from a common center. These folds are not often broader than the body and may be so very narrow that they are easily overlooked. They may be called alae or wings, and constitute a simpler or less highly specialized type of clasping apparatus than the circular bursate type. The alate type is common and very likely characteristic among the Spiruroidea. (Figs. 6, 7.)

There certainly are other types of cuticular grasping organs among nematodes such as those of the trichina and the funnel-shaped organs of Eustrongylides and Hystrichus. But I have not yet had opportunity to study these personally, and do not desire to do more than mention them here.

Among the Acanthocephala the simple forms which have in the hypoderm and lemnisci only a few giant nuclei constitute a group sufficiently distinct from other types to be ranked as a family which I propose to call the Neoechinorhynchidae with Neoechinorhynchus Stiles and Hassall 1905 as the type genus. The family may be characterized as follows:

NEOECHINORHYNCHIDAE Ward. Acanthocephala with hypoderm consisting of a syncitium in which are six giant nuclei, ordinarily arranged so that five lie in the mid-dorsal line and one in the mid-ventral. One lemniscus contains two giant nuclei and the other only one. These nuclei are usually conspicuous on external examination. The proboscis sheath contains only a single layer of muscles. The cement gland is a compact mass. A neck is lacking. The muscles are weakly developed. The lacunar system is supplied only with simple circular connections. 
The type genus of this family has been very fully and accurately described by Van Cleave (1913). He ranked in this genus one species which differs from all others in it in having an elongate proboscis with numerous irregular circles of hooks in the place of the globose proboscis with only three circles of hooks. For this aberrant form I have established the new genus Tanaorhamphus with $T$. longirostris (Van Cleave 1913) as type. The extreme length of the proboscis and the large number of hooks distinguish these forms at sight from those of the genus Neoechinorhynchus. Of other points of difference in structure perhaps the most striking is the constant presence of 16 nuclei in the cement gland of Tanaorhamphus where Neoechinorhynchus has only 8. One notes also that in Tanaorhamphus the hooks of the anterior row are not conspicuously larger than those following, but in Neoechinorhynchus the difference in size is real in all and very marked in most species.

\section{Papers Cited}

Barker, F. D., and Parsons, S. 1914. A New Species of Monostome from the Painted Terrapin, Chrysemys marginata. Zool. Anz., 45: 193-194.

Cole, L. J. 1911. A Trematode Parasite of the English Sparrow in the United States. Bull. Wisc. Nat. Hist. Soc., 9: 42-48, 1 pl.

Cort, W. W. 1915. North American Frog Lung Flukes. Trans. Amer. Micr. Soc., $34: 203-240,3$ pls.

Gilbert, N. C. 1905. Occurrence of Echinostomum spinulosum Rud. Amer. Nat., 39: 925-927, 1 fig.

MacCallum, W. G. 1902. Heronimus chelydrae, nov. gen. nov. sp. A New Monostome Parasite of the American Snapping-Turtle. Centr. Bakt. u. Par., Orig. 32 : 632-636, 2 figs.

Odhner, T. 1910. Nordostafrikanische Trematoden, grösstenteils vom Weissen

Nil. I. Fascioliden. Results Swed. Zool. Exped., 1901, No. 23 A, 170 pp., 6 pls.

Stafford, J. 1904. Trematodes from Canadian Fishes. Zool. Anz., 27: 481-95.

Stunkard, H. W. 1917. Studies on North American Polystomidae, Aspidogastridae, and Paramphistomidae. I1l. Biol. Monogr., 3:7-114, 11 pls.

Van Cleave, H. J. 1913. The Genus Neorhynchus in North America. Zool. Anz., $43: 177-190$.

Ward, Henry B., and Magath, T. B. 1917. Notes on Some Nematodes from Fresh-Water Fishes. Jour. Paras., 3:57-64, 1 pl. 


\section{EXPLANATION OF PLATE}

Figs. 1 to 4.- Apical views of anterior end to illustrate different morphological types among Nematode heads.

Fig. 1.-True lips; tripartite arrangement, in which, however, the dorsal lip has two paillae. Ascaris lumbricoides. (After Leuckart.)

Fig. 2.-Oral capsule; orifice an undivided circle surrounded by six equidistant papillae and showing tripartite esophagus inside and below level of capsule. Cylichnostomum coronatum. (After Looss.)

Fig. 3.-True jaws; bilateral type with mouth a dorsi-ventral slit. Camallanus ancylodirus. (Original.)

Fig. 4.--Radial arrangement; six small protuberances of irregular form, often called lips and jaws but evidently not equivalent morphologically to structures shown in Figures 1 and 3. Note however, the four papillae. Protospirura muris. (After Schneider.)

Fig. 5.-True capsule but bent $60^{\circ}$ dorsad. Longisection of anterior end to show dorsal (secondary) position of mouth in Ancylostoma duodenale. (From Neumann and Mayer after Brumpt.)

Figs. 6, 7.-Posterior end of male showing true alae in ventral aspect. Papillae or ribs shown in outline only.

Fig. 6.-Alae joined at anterior limit. Physaloptera muris-braziliensis. (From Hall after von Drasche.)

Fig. 7.-Alae narrow and not joined. Spiroptera penihamata. (After von Drasche.)

Figs. 8-10.-Posterior end of male showing true bursa. Rays of bursa shown in outline.

Fig. 8.-Bursa with distinct, well separated lobes, from dorsal aspect. Haemonchus contortus. (After Ransom.)

Fig. 9.-Bursa with slight median notch between lobes. Heligmosomum minutum. (From Hall after von Linstow.)

Fig. 10.-Lobes completely fused along median line to form a single organ. Esophagostomum columbianum. (After Ransom.)

Figs. 11 and 14.-Dorsal views of anterior end to illustrate various types of esophagus among nematodes.

Fig. 11.-Muscular esophagus with single region only. Note, however, granular (glandular?) mass close to posterior end. Cylichnostomum auriculatum. (After Looss.)

Fig. 12.-Muscular esophagus divided by distinct transverse partition near center of length. Haplonema immutatum. (After Ward and Magath.)

Fig. 13.-Esophagus with anterior muscular and posterior granular regions clearly distinguishable but not separated by partition from each other. Spinitectus gracilis. (Original.)

Fig. 14.-Esophagus with two regions, viz. anterior muscular and posterior granular, sharply separated by constriction and transverse partition. Camallanus oxycephalus. (Original.) 
WARD-NORTH AMERICAN PARASITIC WORMS
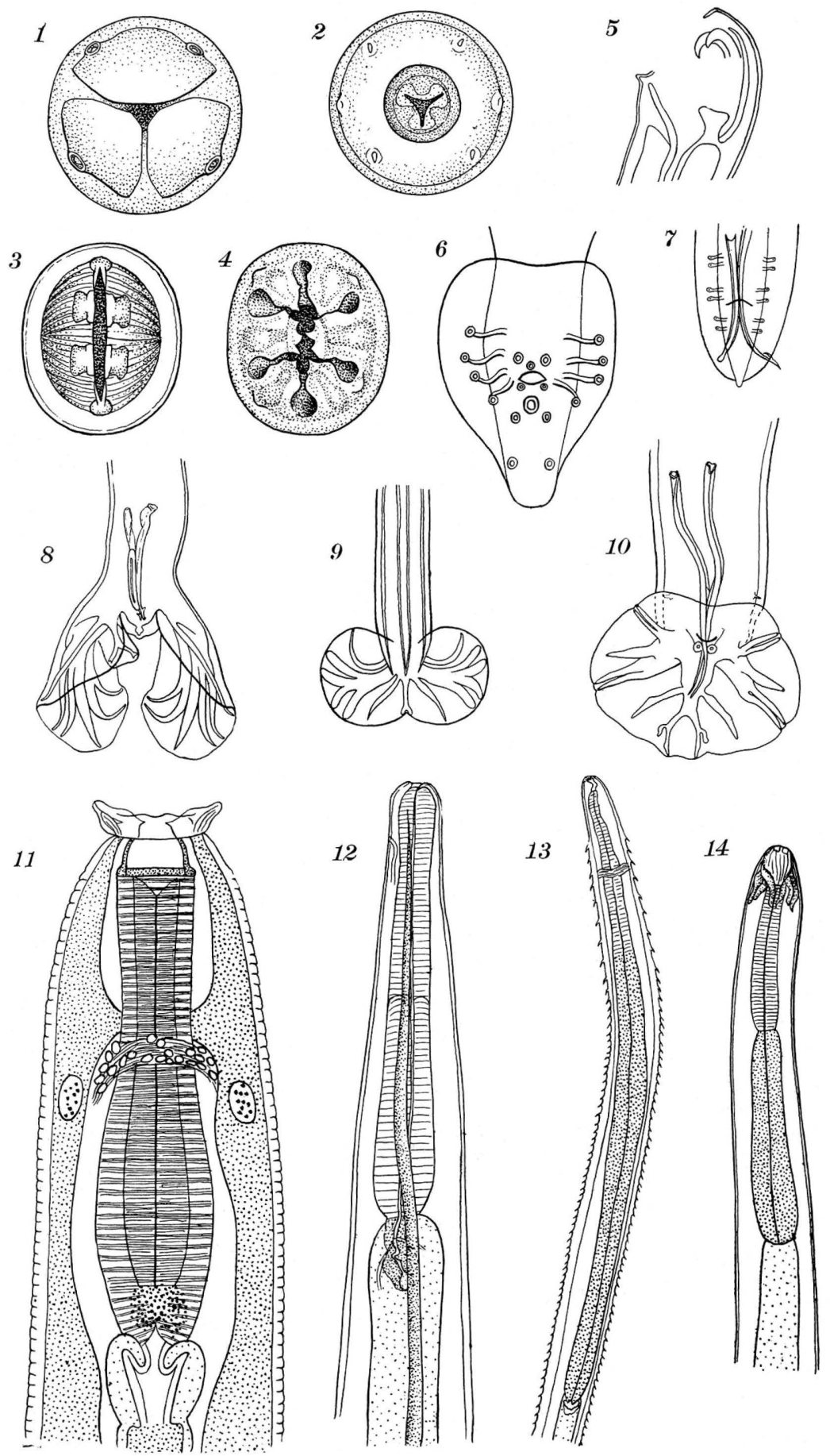